\title{
Sexual transmission of Zika virus in Germany, April 2016
}

C Frank ${ }^{1}$, D Cadar 2 , A Schlaphof 2 , N Neddersen 2 , S Günther 2 , J Schmidt-Chanasit 234 , D Tappe 234

1. Robert Koch Institute, Department for Infectious Disease Epidemiology, Division of Gastrointestinal Infections, Zoonoses and Tropical Infections, Berlin, Germany

2. Bernhard Nocht Institute for Tropical Medicine, WHO Collaborating Centre for Arbovirus and Haemorrhagic Fever Reference and Research, Hamburg, Germany

3. German Centre for Infection Research (DZIF), partner site Hamburg-Luebeck-Borstel, Hamburg, Germany

4. These authors contributed equally to this work

Correspondence: Jonas Schmidt-Chanasit (jonassi@gmx.de)

Citation style for this article:

Frank C, Cadar D, Schlaphof A, Neddersen N, Günther S, Schmidt-Chanasit J, Tappe D. Sexual transmission of Zika virus in Germany, April 2016. Euro Surveill. 2016;21(23): pii=30252. DOI: http://dx.doi.org/10.2807/1560-7917.ES.2016.21.23.30252

Zika virus (ZIKV), an emerging mosquito-borne flavivirus, causes a mild dengue fever-like illness but has recently been associated with neurological disease and severe birth defects. The virus is currently causing a large epidemic in the Americas. Here, we report a male-to-female sexual transmission of ZIKV in Germany in April 2016, following travel to Puerto Rico of the male patient, demonstrated by subsequent seroconversions and molecular identification of identical virus sequences from both patients.

\section{Case descriptions}

On 13 April 2016, the index patient, a 35-year old male German citizen, presented at his general practitioner with signs and symptoms of a common cold. He had returned to northern Germany on 5 April after a oneweek stay in Puerto Rico. At the time, a Zika virus (ZIKV) outbreak was ongoing in Puerto Rico [1]. On 6 April, the patient felt weak, but attributed his symptoms to travel-associated exhaustion. One day later, he noticed swollen nuchal lymph nodes. From 8 to 10 April his joints (fingers, knees and ankles) were swollen and painful, such that he could barely walk, and he had a hardly visible but very itchy rash. Neither conjunctivitis nor fever were present. After cessation of these symptoms, the patient developed symptoms of an upper respiratory tract infection lasting for about one week, dominated by a runny nose and persistent sinus headaches. A serum sample of 13 April was negative for Dengue virus (DENV) NS1 antigen, but showed an ZIKV antibody IgM titre of 1:1,280 and an IgG titre of 1:20,480 by indirect immunofluorescence test (IIFT, reference: 1 1:20) [2]. Results were also positive for anti-ZIKV IgM and IgG in a commercial ELISA (AntiZika Virus ELISA, EUROIMMUN, Lübeck, Germany) [2]. Consequently, Zika virus disease (ZVD) was diagnosed (Figure 1).
On 17 April, his 29-year-old female partner who had not been travelling, also developed upper respiratory tract infection. On 20 April, she additionally noted swollen lymph nodes in the neck. The following morning she noticed having unusually red cheeks and a non-itchy rash which spread within one to two hours to her entire body, except the palms of her hands. Fever and conjunctivitis were not noted. On the same day, 21 April, the index patient was informed about his ZIKV infection and his partner was tested for ZIKV infection, too. She was negative for anti-ZIKV IgG and IgM in IIFT and ELISA, as well as DENV NS1-Antigen, however, ZIKV RNA was detected in serum and urine by real time RT-PCR (RealStar Zika Virus RT-PCR Kit 1.0, altona Diagnostics, Hamburg, Germany) and she was diagnosed with ZVD (Figure 1). ZIKV RNA was not detected in saliva. During the next days she developed swollen and painful joints affecting some fingers and the ankles. Symptoms resolved by 25 April.

The male patient had ZIKV RNA in urine, but not in saliva and serum 13 days after onset of symptoms. One semen sample taken 45 days after onset of symptoms tested positive for ZIKV RNA and the RNA load was $6 \times 10^{4}$ copies/mL. In contrast, urine and serum samples were then both negative for ZIKV RNA. ZIKV could not be isolated in cell culture from semen. The female patient tested positive for anti-ZIKV-IgM and IgG in the IIFT and ELISA 34 days after onset of symptoms demonstrating ZIKV seroconversion. Her urine and serum samples then tested negative for ZIKV RNA.

\section{Sequence analysis from urine samples}

A fragment of the ZIKV NS5 gene (ca $400 \mathrm{bp}$, excluding primers) could be amplified from the urine of both patients (GenBank accession numbers KX253994 and KX 253995). Sequence analysis showed $100 \%$ identity of the samples from both patients (exhibiting only one 
Sequence of events in sexually transmitted Zika virus infection from male traveller returning from Puerto Rico, to his female partner, Germany, April 2016

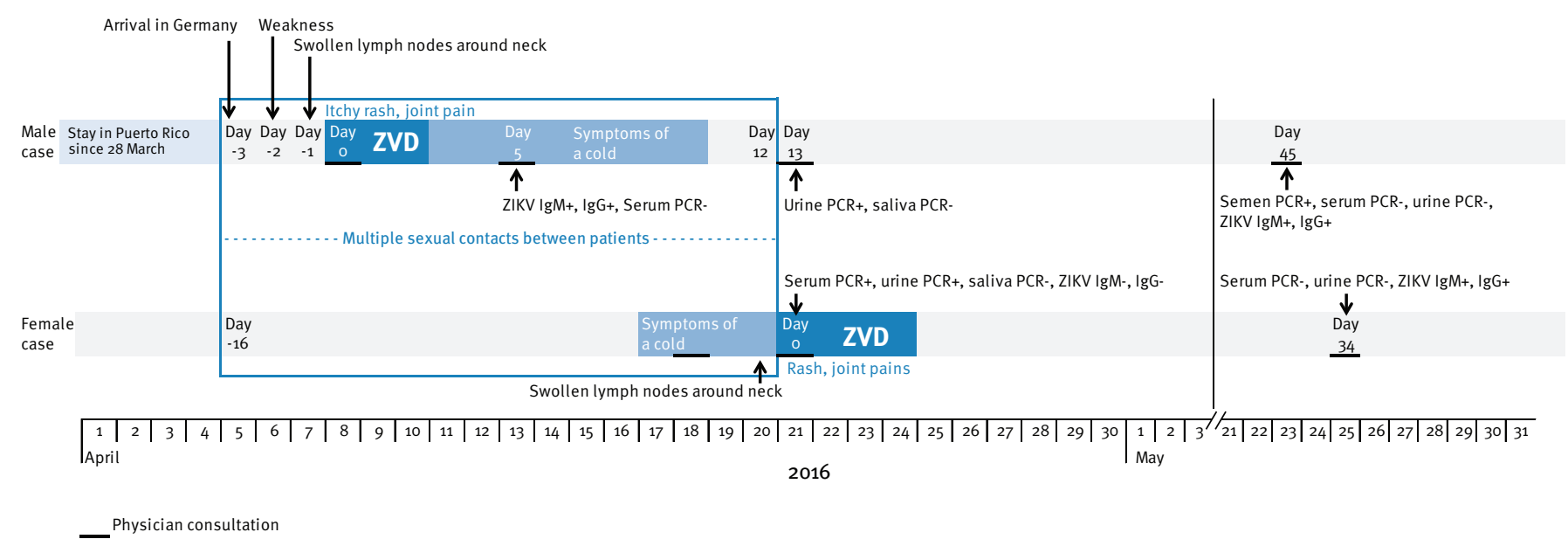

ZIKV: Zika virus; ZVD: Zika virus disease.

synonymous substitution in comparison to the closely related ZIKV strains from GenBank). Based on the phylogeny the two sequences clustered together with the recently detected ZIKV strains from Puerto Rico and other Central and South American countries into the same ZIKV outbreak clade from the Asian ZIKV lineage (Figure 2).

The female patient did not recall any mosquito bites during the previous few weeks, when it was spring. In addition, ZIKV vector mosquito species Aedes aegypti or Ae. albopictus have not been described anywhere in northern Germany, thus a mosquito-borne transmission was regarded as highly unlikely. She had last been in an area at risk for ZIKV infection between Christmas 2015 and mid-January 2016, when the couple had visited a later ZIKV-affected country together. A male-tofemale sexual ZIKV transmission was assumed given the sequence of clinical symptoms in the two patients and subsequent demonstration of seroconversion in the female patient. The molecular analyses and prolonged detection of ZIKV RNA in semen support the assumption. The couple reported multiple sexual contacts (vaginal intercourse without condoms) from the day of his return from travel ( 5 April) to onset of her rash (21 April), i.e. slightly before and up to 12 days after his onset of ZVD-like symptoms (Figure 1). She is taking oral contraceptives and was not pregnant at the time of infection. He did not report haematospermia or symptoms of prostatitis.

\section{Background}

ZIKV is an emerging mosquito-borne flavivirus that causes a mild, dengue fever-like illness termed ZVD [3]. The most common symptoms are rash, arthralgia, and conjunctivitis. ZIKV infection has recently been associated with neurological disease and severe birth defects [4-6]. The Asian genotype of ZIKV is currently causing a large epidemic in the Americas [7]. ZIKV infection has also been detected in returning travellers from endemic and epidemic regions $[8,9]$. The virus is most likely transmitted through bites of infected $A e$. aegypti and Ae. albopictus mosquitoes $[10,11]$. Sexual transmission, which had first been assumed in 2008 in the United States (US) in the wife of a man who had previously been to Senegal [12]. Circumstantial evidence suggested possible sexual transmission by vaginal intercourse in the days after the return of the male patient and before onset of symptoms of ZIKV infection and concomitant prostatitis. He had developed haematospermia four days after disease onset. Further potential evidence for sexual transmissibility was seen

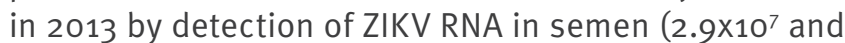
$1.1 \times 10^{7}$ copies $/ \mathrm{mL}$ ) and urine of a patient from Tahiti with haematospermia some weeks after symptoms compatible with ZVD. ZIKV was successfully cultured from semen and urine [13]. Additional evidence was reported from the United Kingdom by detection of ZIKV RNA from semen 27 and 62 days after onset of febrile illness in a man who had returned from the Cook Islands in 2014, and a prolonged potential for sexual transmission was discussed [14]. A male-to-male sexual transmission after anal sex was reported from the US in January 2016, after travel to Venezuela of the index patient, as shown by positive anti-ZIKV IgM and IgG detection in both patients. Haematospermia and symptoms of prostatitis were absent [15]. Retrospective analyses showing serological evidence of ZIKV infection suggested sexual transmission in an Italian couple after return of the male partner from Thailand [16]. A case series with incomplete results has been published from the US [17], describing infections in women 
Maximum likelihood phylogenetic tree, sexually transmitted Zika virus infection from male traveller returning from Puerto Rico, to his female partner, Germany, April 2016

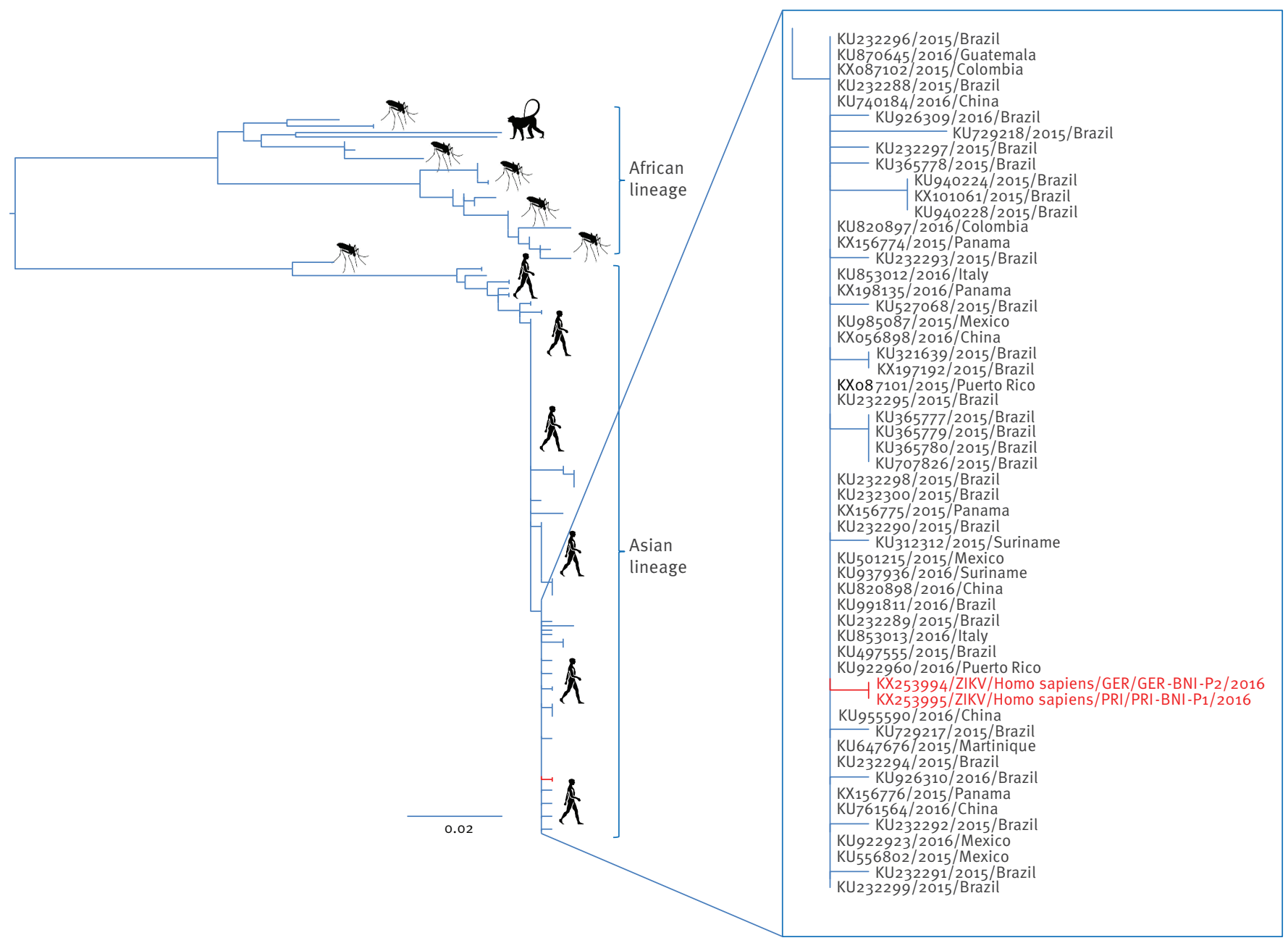

In the entries in red, $\mathrm{P}$ represent the two patients described here.

The tree is based on nt sequences of the partial NS 5 gene (ca $380 \mathrm{bp}$ ). It shows the placement of the ZIKV virus strains that were characterised directly from the urine (obtained from both patients, $\mathrm{P}_{1}$ and $\mathrm{P}_{2}$ ) in comparison to all available Zika virus (ZIKV) sequences in GenBank. The analysis was performed under the best fit nt substitution model identified as the Tamura-Nei (TN93+ + ) model using jModelTest v2. To assess the robustness of each node, a bootstrap resampling process was performed (1,000 replicates) using the nearest neighbour interchange (NNI) branch-swapping method available in PhyML v3.0. For better visualisation of the position of the ZIKV strains identified in both patients we magnified the area of the American ZIKV outbreak clade which indicates the location of ZIKV from this study (red). The taxon information includes the GenBank accession number, isolation/detection year and country where the virus was isolated/detected. Scale bar indicates mean number of nt substitutions per site.

following sexual contacts with their male partners after these had travelled in Central America and the Caribbean. Recently, sexual transmission was shown in a French woman after unprotected vaginal and oral intercourse with her male partner who had previously travelled to Brazil. ZIKV was detected by PCR and cul-

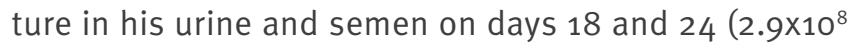
and $3.5 \times 10^{7}$ copies $/ \mathrm{mL}$ in semen) following a period of symptomatic ZIKV infection. He did not report haematospermia [18]. A roughly 100,000 times higher ZIKV load in semen $\left(8.6 \times 10^{10}\right.$ copies $\left./ \mathrm{mL}\right)$ than in blood was recently demonstrated in a traveller returning to France from Brazil and French Guyana [19].

\section{Conclusions}

Here we describe a sexually transmitted ZIKV infection in Germany. The ZIKV RNA load in semen on day 45 post symptom onset was significantly lower than in previous reports $[13,18,19]$. Sexual transmission of ZIKV is of special concern during pregnancy and specific guidelines for prevention have been published $[4,20]$. In order to protect the fetus, the European Centre for Disease Prevention and Control (ECDC) notes that male travellers returning from affected areas should consider using a condom with a pregnant partner until the end of pregnancy [4]. In addition, the World Health Organization (WHO) now advises male travellers returning from areas with ongoing ZIKV transmission 
to practice safer sex or consider abstinence for at least eight weeks after their return in order to reduce the potential risk of onward sexual transmission. This period extends to at least six months if symptoms of ZIKV infection occur, during or after travel [20]. In contrast to previously described index cases involved in sexual transmission, our case did not notice haematospermia. It will be important to elucidate if haematospermia is associated with a higher ZIKV load in semen and if there is a correlation with the risk of sexual transmission of ZIKV. In addition, experimental data on ZIKV infection of semen are needed to substantiate the epidemiological findings.

\section{Conflict of interest}

None declared.

\section{Authors' contributions}

Wrote the manuscript: CF, DC, SG, JSC, DT

Performed laboratory or epidemiological investigations: CF, AS, NN, DC, JSC, DT.

Performed data analysis: CF, DC, JSC, DT.

\section{References}

1. Dirlikov E, Ryff KR, Torres-Aponte J, Thomas DL, Perez Padilla J, Munoz-Jordan J, et al. Update: Ongoing Zika Virus Transmission - Puerto Rico, November 1, 2015-April 14 2016. MMWR Morb Mortal Wkly Rep. 2016;65(17):451-5. DOI: 10.15585/mmwr.mm6517e2 PMID: 27149205

2. Huzly D, Hanselmann I, Schmidt-Chanasit J, Panning M. High specificity of a novel Zika virus ELISA in European patients after exposure to different flaviviruses. Euro Surveill. 2016;21(16):30203. DOI: 10.2807/1560-7917. ES.2016.21.16.30203 PMID: 27126052

3. Ginier M, Neumayr A, Günther S, Schmidt-Chanasit J, Blum J. Zika without symptoms in returning travellers: What are the implications?Travel Med Infect Dis. 2016;14(1):16-20. DOI: 10.1016/j.tmaid.2016.01.012 PMID: 26876061

4. European Centre for Disease Prevention and Control (ECDC). Rapid risk assessment: Zika virus disease epidemic: potentia association with microcephaly and Guillain-Barré syndrome, sixth update - 20 May 2016. Stockholm: ECDC. Available from: http://ecdc.europa.eu/en/publications/Publications/zika\%20 virus\%2orapid\%20risk\%20assessment\%2010-05-2016.pdf

5. Driggers RW, Ho CY, Korhonen EM, Kuivanen S, Jääskeläinen AJ, Smura T, et al. Zika Virus Infection with Prolonged Maternal Viremia and Fetal Brain Abnormalities. N Engl J Med. 2016;374(22):2142-51. DOI: 10.1056/NEJMoa1601824 PMID: 27028667

6. Cao-Lormeau VM, Blake A, Mons S, Lastère S, Roche C, Vanhomwegen J, et al. Guillain-Barré Syndrome outbreak associated with Zika virus infection in French Polynesia: a case-control study. Lancet. 2016;387(10027):1531-9. DOI: 10.1016/S0140-6736(16)00562-6 PMID: 26948433

7. de M Campos R, Cirne-Santos C, Meira GL, Santos LL, de Meneses MD, Friedrich J, et al. Prolonged detection of Zika virus RNA in urine samples during the ongoing Zika virus epidemic in Brazil. J Clin Virol. 2016;77:69-70. DOI: 10.1016/j. jCv.2016.02.009 PMID: 26921737

8. Tappe D, Rissland I, Gabriel M, Emmerich P, Gunther S, Held G, et al. First case of laboratory-confirmed Zika virus infection imported into Europe, November 2013. Euro Surveill. 2014;19(4):20685. DOI: 10.2807/1560-7917.ES2014.19.4.20685 PMID: 24507467

9. Zammarchi L, Tappe D, Fortuna C, Remoli ME, Günther $\mathrm{S}$, Venturi G, et al. Zika virus infection in a traveller returning to Europe from Brazil, March 2015. Euro Surveill. 2015;20(23):21153. DOI: 10.2807/1560-7917.ES2015.20.23.21153 PMID: 26084316

10. Chouin-Carneiro T, Vega-Rua A, Vazeille M, Yebakima A, Girod R, Goindin D, et al. Differential Susceptibilities of Aedes aegypti and Aedes albopictus from the Americas to Zika Virus. PLoS Negl Trop Dis. 2016;10(3):e0004543. doi: DOI: 10.1371/ journal.pntd.0004543. eCollection 2016 Mar.

11. Guzzetta G, Poletti P, Montarsi F, Baldacchino F, Capelli G, Rizzoli A, et al. Assessing the potential risk of Zika virus epidemics in temperate areas with established Aedes albopictus populations. Euro Surveill. 2016;21(15):30199. DOI: 10.2807/1560-7917.ES.2016.21.15.30199 PMID: 27104366

12. Foy BD, Kobylinski KC, Chilson Foy JL, Blitvich BJ, Travassos da Rosa A, Haddow AD, et al. Probable non-vector-borne transmission of Zika virus, Colorado, USA. Emerg Infect Dis. 2011;17(5):880-2. DOI: 10.3201/eid1705.101939 PMID: 21529401

13. Musso D, Roche C, Robin E, Nhan T, Teissier A, Cao-Lormeau VM. Potential sexual transmission of Zika virus.Emerg Infect Dis. 2015;21(2):359-61. DOI: 10.3201/eid2102.141363 PMID: 25625872

14. Atkinson B, Hearn P, Afrough B, Lumley S, Carter D, Aarons EJ, et al. Detection of Zika Virus in Semen. Emerg Infect Dis. 2016;22(5):940. DOI: 10.3201/eid2205.160107 PMID: 27088817

15. Deckard DT, Chung WM, Brooks JT, Smith JC, Woldai S, Hennessey M, et al. Male-to-Male Sexual Transmission of Zika Virus - Texas, January 2016. MMWR Morb Mortal Wkly Rep. 2016;65(14):372-4. DOI: 10.15585/mmwr.mm6514a3 PMID: 27078057

16. Venturi G, Zammarchi L, Fortuna C, Remoli ME, Benedetti E, Fiorentini $C$, et al. An autochthonous case of Zika due to possible sexual transmission, Florence, Italy, 2014. Euro Surveill. 2016;21(8):30148. DOI: 10.2807/1560-7917. ES.2016.21.8.30148 PMID: 26939607

17. Hills SL, Russell K, Hennessey M, Williams C, Oster AM, Fischer M, et al. Transmission of Zika Virus Through Sexua Contact with Travelers to Areas of Ongoing Transmission Continental United States, 2016. MMWR Morb Mortal Wkly Rep. 2016;65(8):215-6. DOI: 10.15585/mmwr.mm6508e2 PMID: 26937739

18. D’Ortenzio E, Matheron S, Yazdanpanah Y, de Lamballerie X, Hubert B, Piorkowski G, et al. Evidence of Sexual Transmission of Zika Virus. N Engl J Med. 2016;374(22):2195-8. DOI: $10.1056 /$ NEJMc1604449 PMID: 27074370

19. Mansuy JM, Dutertre M, Mengelle C, Fourcade C, Marchou $B$, Delobel $P$, et al. Zika virus: high infectious viral load in semen, a new sexually transmitted pathogen? Lancet Infect Dis. 2016;16(4):405. DOI: 10.1016/S1473-3099(16)00138-9 PMID: 26949027

20. World Health Organization (WHO). Prevention of sexual transmission of Zika virus. Geneva: WHO. 7 Jun 2016. Available from: http://apps.who.int/iris/bitstream/10665/204421/1/ WHO_ZIKV_MOC_16.1_eng.pdf?ua=1

\section{License and copyright}

This is an open-access article distributed under the terms of the Creative Commons Attribution (CC BY 4.0) Licence. You may share and adapt the material, but must give appropriate credit to the source, provide a link to the licence, and indicate if changes were made.

This article is copyright of the authors, 2016. 